\title{
Non-opioid Analgesics and the Endocannabinoid System
}

\author{
Ruhan Deniz Topuz, Özgür Gündüz, Çetin Hakan Karadağ, Ahmet Ulugöl
}

Department of Medical Pharmacology, Trakya University School of Medicine, Edirne, Turkey

Non-steroidal anti-inflammatory drugs produce antinociceptive effects mainly through peripheral cyclooxygenase inhibition. In opposition to the classical non-steroidal anti-inflammatory drugs, paracetamol and dipyrone exert weak anti-inflammatory activity, their antinociceptive effects appearing to be mostly due to mechanisms other than peripheral cyclooxygenase inhibition. In this review, we classify classical non-steroidal anti-inflammatory drugs, paracetamol and dipyrone as "non-opioid analgesics" and discuss the mechanisms mediating participation of the endocannabinoid system in their antinociceptive effects. Non-opioid analgesics and their metabolites may activate cannabinoid receptors, as well as elevate endocannabinoid levels through different mechanisms: reduction of endocannabinoid degradation via fatty acid amide hydrolase and/or cyclooxygenase-2 inhibition, mobilization of arachidonic acid for the biosynthesis of endocannabinoids due to cyclooxygenase inhibition, inhibition of endocannabinoid cellular uptake directly or through the inhibition of nitric oxide synthase production, and induction of endocannabinoid release.

Keywords: Dipyrone, endocannabinoids, NSAIDs, paracetamol
Cannabinoids are a heterogenous group of compounds, which activate the cannabinoid receptors found throughout the body. They are not only found in the cannabis plant, but also produced by the human body (endocannabinoids). In addition, there are artificially synthetized synthetic cannabinoids, who are functionally similar to $\Delta^{9}$-tetrahydrocannabinol (THC), the main psychoactive and analgesic compound found in the plant $(1,2)$. All of these compounds exert their effects via interaction with cannabinoid-1 (CB1) and cannabinoid-2 (CB2) receptors $(3,4)$. Both CB1 and CB2 receptors are $\mathrm{G}$-protein-coupled receptors, primarily exhibiting $\mathrm{G}_{\mathrm{i} / \mathrm{o}}$ signaling mechanisms. CB1 receptors are mainly expressed in brain structures, but also in peripheral tissues; on the other hand, CB2 receptors are expressed most abundantly in immune system cells in the periphery. Many of the unwanted effects of cannabinoid receptor agonists are caused via $\mathrm{CB} 1$ receptors located in the central nervous system $(5,6)$.

Endocannabinoid system is comprised of $\mathrm{CB} 1$ and $\mathrm{CB} 2$ receptors, their endogenous lipid ligands (endocannabinoids) and the enzymes involved in their biosynthesis and inactivation. Endocannabinoids are derived from arachidonic acid (AA); anandamide [arachidonyl ethanolamide (AEA)] and 2-arachydonoyl-glycerol (2-AG) are best characterized and considered to be the main endocannabinoids $(6,7)$. AEA and 2-AG are produced at post-synaptic neurons with twostep processes. Phosphatidylethanolamine is converted to $\mathrm{N}$-acylphosphatidylethanolamine (NAPE) by the enzyme N-acyltransferase; then NAPE is hydrolyzed to N-acylethanolamines, such as AEA, by a NAPE-selective phospholipase D (NAPE-PLD). On the other hand, 2-AG is synthesized from diacylglycerol (DAG) by DAG lipase, following production of DAG from inositol phospholipids (7-9). Endocannabinoids are synthesized "on demand", released immediately, act in an autocrine or paracrine manner, and their biological actions rapidly terminate $(8,10)$. AEA and 2-AG are removed from the extracellular space by a cellular uptake mechanism, followed by enzymatic inactivation. Relatively little is known about 2-AG uptake, but N-arachydonoyl-phenolamine (AM-404), the metabolite of paracetamol, is known to inhibit uptake of AEA. This is important with regard to the interaction of the analgesics and the endocannabinoid system, the main concept of this review. AEA is predominantly degraded to AA and ethanolamine by fatty acid amide hydrolase (FAAH), whereas 2-AG is predominantly metabolized to AA and glycerol by monoacylglycerol lipase (MAGL), and to a lesser extent by FAAH $(9,11)$. In addition to FAAH and MAGL, AEA and 2-AG are demonstrated to be good substrates for cytochrome p450 monooxygenases, lipooxygenases and cyclooxygenases, mainly COX-2 (12-14). Besides FAAH and MAGL inhibition, these pathways of degradation are also important in elevation of endocannabinoid levels; since all non-steroidal anti-inflammatory drugs (NSAIDs) inhibit COX enzymes, COX-2 inhibition may participate in the antinociceptive effects of analgesic drugs.

Cannabis has been used for the management of pain for centuries, and numerous experimental and clinical research works have found effectiveness of the plant's constituents, endocannabinoids and synthetic cannabinoids in different pain models (15-17). However, the number of approved cannabinoid-based medicines is small.

\footnotetext{
Address for Correspondence: Ahmet Ulugöl, Department of Medical Pharmacology, Trakya University School of Medicine, Edirne, Turkey Phone: +902842353925 e-mail: aulugol@trakya.edu.tr ORCID: orcid.org/0000-0003-4643-1124 
Nausea and vomiting related to chemotherapy, anorexia related to AIDS, and chronic pain and spasticity associated with multiple sclerosis are the conditions that cannabinoids are approved for $(6,18)$, but they are generally prescribed as an alternative and/or potential adjunctive agents in these indications. When targeting the endocannabinoid system as a promising future therapeutic strategy (19), inhibition of FAAH, MAGL and COX-2 seems to be one of the most attractive approaches $(6,10,19,20)$. Such is due to the role of these enzymes in inactivation of endocannabinoids, with their inhibition increasing local endocannabinoid levels. The endocannabinoid system can be the target of many therapies, as it is involved in a number of physiological regulation pathways, but in this review we will focus mostly on modulation on nociception. NSAIDs exhibit moderate analgesic, anti-inflammatory and antipyretic properties; they are the most common pain relief medicines in the world. The principal mechanism of action of NSAIDs is inhibiting the activity of COX enzymes, and thereby reducing the production of prostaglandins (21). However, accumulating evidence shows that NSAIDs' therapeutic effects involve mechanisms other than COX inhibition, potentially including interaction with nitric oxide, opioidergic, monoaminergic and cholinergic systems (22). Involvement of the endocannabinoid system in the analgesic effects of NSAIDs also seems as a likely mechanism. Similar to cannabinoids/endocannabinoids $(23,24)$, NSAIDs inhibit pain at the peripheral, spinal and supraspinal levels $(25,26)$. Paracetamol and dipyrone are two different analgesic drugs, not being considered as classical NSAIDs, as they possess very little anti-inflammatory activity. However, the endocannabinoid system has been shown to participate in the antinociceptive actions of both NSAIDs, and paracetamol and dipyrone in recent years (27-30). In this review, we group classical NSAIDs, paracetamol and dipyrone together under the name of "non-opioid analgesics" and focus on the contribution of the endocannabinoid system for the antinociceptive effects of these analgesic drugs.

\section{Link between classical NSAIDs and the endocannabinoid}

$$
\text { system }
$$

Although the primary mechanism of action of NSAIDs is inhibition of COX enzymes, which are responsible for the production of prostaglandins, their ability to inhibit FAAH activity, responsible for the degradation of AEA, has also been shown. Augmenting endocannabinoid tonus locally, by inhibiting the degradative enzymes, may provide local efficacy in tissues, contributing for the control of nociception. In 1996, the potent anti-inflammatory drug indomethacin was suggested to reduce FAAH activity in the mouse uterus both in vivo and in vitro (31). Then, in a series of experiments, Fowler's research group reported that several acidic NSAIDs, including ibuprofen, ketorolac, flurbiprofen, and some of their primary metabolites, inhibited FAAH (32-34). The inhibitory potency of these NSAIDs was relatively low, but increased 5-10fold as the assay $\mathrm{pH}$ was reduced (35-37). These are very important findings, considering lowered $\mathrm{pH}$ in inflamed tissues together with effectiveness of local administrations and when acidic drugs are accumulated in these tissues. Accordingly, locally administered ibuprofen and rofecoxib produce synergistic effects with AEA, and this effect is blocked by a CB1 receptor antagonist $(38,39)$. In a related study, indomethacin was shown to reduce carrageenaninduced edema, and a CB2 receptor antagonist was effective in preventing the NSAID's action (40). In these studies, reduction of AEA metabolism via inhibition of FAAH activity is proposed as the mechanism of action for NSAIDs-induced antinociception; however, it should be taken into consideration that the inhibition of FAAH by NSAIDs does not appear to be potent $(27,34,41)$.

Besides FAAH inhibition, another way of elevating endocannabinoid tonus via preventing their metabolism is COX-2 inhibition. The principal endocannabinoids AEA and 2-AG are good substrates for COX-2, producing prostaglandinethanolamides (prostamides) and prostaglandin-glycerol esters; a reduction in the levels of these proinflammatory and pronociceptive mediators may also contribute for their antinociceptive activity $(12,13)$. There is an increasing interest on differential effects of NSAIDs on COX isoenzymes. Duggan et al. (42) indicated that (R) enantiomers of ibuprofen, naproxen and flurbiprofen are potent substrate-selective inhibitors of endocannabinoid oxygenation by COX-2; these NSAIDs are considered to be inactive as COX-2 inhibitors. Similarly, ibuprofen, mefamic acid and flurbiprofen are more potent inhibitors of COX-2-cyclooxygenation of 2-AG than of AA (42-44). Ibuprofen also exerts potent inhibition of AEA cyclooxygenation compared to AA oxygenation (41). Endocannabinoid-preferring COX inhibitors appear to be among potential novel analgesics; simultaneous FAAH and COX inhibition also seems to be an attractive target $(27,45,46)$.

Increase in endocannabinoid tonus can be reached not only by decreasing their metabolism via inhibition of degradative enzymes, but also by augmenting endocannabinoid biosynthesis. Since AA is also important in endocannabinoid synthesis, COX inhibition probably provides more AA for endocannabinoid synthesis rather than prostaglandin synthesis $(22,47)$. Indeed, it has been suggested that AA mobilization increases AEA production (48). Therefore, it seems that another mechanism implicated in the participation of endocannabinoids in NSAIDs' effects is shunting of free AA from prostaglandin synthesis to endocannabinoid synthesis, although how AA participates in such production is not known.

Regarding the involvement of the endocannabinoid system in the analgesic effects of NSAIDs, Gühring et al. (49) proposed that, first, at the spinal level, indomethacin induces a shift of AA metabolism toward endocannabinoid synthesis; second, indomethacin lowers nitric oxide production, reducing activation of endocannabinoid transporters and thus breakdown of endocannabinoids; and third, it inhibits FAAH and hence enhances endocannabinoid levels. Spinal administration of flurbiprofen and intracerebroventricular administration of celecoxib also exerts endocannabinoiddependent antinociception (50,51). Co-administration of ketorolac and the mixed CB1/CB2 cannabinoid receptor agonist WIN $55,212-2$ produces an additive antinociceptive interaction in an inflammatory visceral pain model (16). Co-administration of a FAAH inhibitor and the COX inhibitor diclofenac also elicits a synergistic antinociceptive effect in the acetic acid model of visceral nociception (45). Contradictory findings are also worth mentioning; Silva et al. (52) reported that cannabinoid receptors do not seem to be involved in the peripheral antinociceptive 
mechanisms of dipyrone, diclofenac and indomethacin, following intra-plantar administration of the NSAIDs. Antagonism of cannabinoid receptors also does not influence diclofenac-induced antinociception when given systemically (53). In another study, neither the CB1 nor the CB2 antagonist blocked the effects of the NSAIDs in animals chronically administered with THC (54). Staniaszek et al. (55) concluded that nimesulide inhibits spinal neuronal responses in a CB1-dependent way, but they did not detect a concomitant elevation in AEA or 2-AG levels.

\section{Link between paracetamol and the endocannabinoid system}

Paracetamol (acetaminophen) is one of the most widely used drugs as an antipyretic and analgesic. Unlike classical NSAIDs, paracetamol does not exert any anti-inflammatory activity, whereas its analgesic activity is similar to that of NSAIDs. Inhibition of peripheral COX enzymes does not appear to be primarily responsible for the antinociceptive activity of paracetamol; but probably some central mechanisms, including the endocannabinoid system, participate in these effects (56). Inhibition of central COX, modulation of serotonergic and opioidergic systems, and inhibition of nitric oxide synthetases (NOS) are among the proposed mechanisms (57-60). In 2005, Högestätt et al. (61) reported that paracetamol, following deacetylation to p-aminophenol, is FAAH-dependently conjugated with AA in the brain and spinal cord to form the bioactive AM404. Then, CB1 receptors have been demonstrated to participate in both local and systemic antinociceptive effects of paracetamol $(62,63)$. In their detailed research, Mallet et al. (28) suggested that AM-404 indirectly activates the supraspinal CB1 receptors, which in turn reinforces the activity of descending serotonergic inhibitory pathways. The metabolite AM-404 was already known to have the ability of inhibiting uptake of AEA; moreover, it has also shown to be a central COX inhibitor, a FAAH inhibitor, a weak CB1 activator, and a potent activator of TRPV1 (46,61,64-67). All of these properties of AM-404 may be related to its mediatory role in the antinociceptive activity of paracetamol. Results of another study implied that modulation of the endocannabinoid system mediates the synergistic antinociceptive effects of paracetamol combinations (68). There are also some contrary data, indicating that cannabinoid receptor antagonists do not block the effects of paracetamol, but these results were obtained in animals following chronic administration of THC or in an acute visceral pain model $(54,69)$.

In most of these studies, pharmacological blockade or genetic deletion of cannabinoid receptors have been performed. Our group measured local endocannabinoid and $\mathrm{N}$-acylethanolamide levels in the brain and spinal cord of rats, in order to observe the interaction of paracetamol and endocannabinoids directly; we observed an increase in 2-AG levels in the PAG and the RVM 12 $\mathrm{h}$ after paracetamol administration, but a decrease in AEA levels in the RVM and spinal cord (70). There are also studies on the contribution of the endocannabinoid system to some other effects of paracetamol. It was suggested that paracetamol exhibits a dosedependent anxiolytic effect in mice via cannabinoid CB1 receptors (71). Paracetamol was also shown to enhance social behavior and cortical cannabinoid levels in mice in a CB1-mediated way
(72). On the other hand, antagonism of cannabinoid CB1 and $\mathrm{CB} 2$ receptors does not prevent the antipruritic effect of systemic paracetamol (73).

\section{Link between dipyrone and the endocannabinoid system}

Dipyrone (metamizole) is another worldwide used antipyretic and analgesic drug. Unlike classical NSAIDs, but similar to paracetamol, it possesses little anti-inflammatory activity. Despite intensive research, the precise mechanism underlying the antinociceptive effect of dipyrone is still unknown. Rather than peripheral COX inhibition, it has been suspected for a long time that dipyrone elicits centrally-mediated antinociceptive action (74-76). Initially, research has focused on the concept that endogenous opioids are involved in dipyrone's antinociception. When microinjected into the PAG, dipyrone exerts antinociceptive effects mediated by endogenous opioids of the RVM (77), which then triggers descending inhibition of spinal nociception (78). The role of endogenous opioids in the spinal cord was also demonstrated (79). In another study, PAG-administered dipyrone induced development of tolerance in rats (80). When administered intravenously, dipyrone also causes anti-nociception by activating the endogenous opioid system (81). Other than its interaction with endogenous opioids, dipyrone is suggested to possess (weak) antinociceptive activity by classical COX inhibition (82), and by activation of the L-arginine-nitric oxide pathway and subsequent KATP channel opening (83), although there are some opposite findings $(84,85)$.

In 2012, Rogosch et al. (29) demonstrated that two unknown metabolites of dipyrone form in the brain and spinal cord. FAAH seems to be responsible for the formation of these metabolites, and once formed, they bind weakly to cannabinoid receptors, but are modest inhibitors of COX-1 and -2 . Then, it was shown that microinjection of dipyrone into the PAG elicits antinociception via $\mathrm{CB} 1$ receptors in an inflammatory pain model (86). There are studies that suggest mechanisms other than the endocannabinoid system for the antinociceptive effects of dipyrone, but these results were obtained under non-inflammatory conditions $(30,87)$. However, the majority of the reports point to the important role of the endocannabinoid system in antinociception induced by dipyrone. It is suggested that activation of $\mathrm{CB} 1$, but not $\mathrm{CB} 2$ receptors, together with neuronal $\mathrm{K}_{\mathrm{ATP}}$ opening is involved in the antihyperalgesic effect of dipyrone metabolites (88). These novel metabolites reduce the activity of ON-cells and enhance the activity of OFFcells in the RVM (25). Importantly, Crunfli et al. (47) indicated that the endocannabinoid system, especially CB1 receptors, is involved in analgesia, catalepsy and hypolocomotion induced by systemic dipyrone. They hypothesized that COX and FAAH inhibition together may increase endocannabinoid availability and exhibit the above-mentioned effects via CB1 receptor stimulation. In accordance with these reports, a computational analysis suggested dipyrone metabolite 4-methylaminoantipyrine as a CB1 receptor agonist (89). In the research mentioned in the paracetamol section, we also measured local endocannabinoid levels in the brain and spinal cord of rats following systemic dipyrone administration; dipyrone exerts no action on 2-AG levels, but unexpectedly 
leads to a reduction in AEA levels in the RVM and spinal cord (70). In a very recent study, dipyrone, following hydrolysis to its active metabolite 4-methylaminoantipyrine, exerted a local antihyperalgesic effect partially dependent on CB2 and kappaopioid receptors (90). Regarding studies that focus on domains beyond nociception, unlike paracetamol, systemic dipyrone does not exert anxiolytic-like effects in mice (91).

Cannabinoids modulate nociception at the peripheral, spinal and supraspinal levels $(23,24)$. After activating supraspinal cannabinoid receptors, cannabinoids inhibit the presynaptic release of GABA via CB1 receptors in the lateral-ventrolateral PAG and RVM, and hence increase the postsynaptic neuron activity (92-95). In addition to their peripheral actions, non-opioid analgesics and/ or their metabolites may augment endocannabinoid levels and/or directly activate cannabinoid receptors, facilitating the activity of descending inhibitory pathways, and thus decreasing nociceptive transmission.
We conclude that the endocannabinoid system may participate in the antinociceptive effects of non-opioid analgesics via several mechanisms (Figure 1):

1- Activation of cannabinoid CB1 receptors (peripheral, spinal, supraspinal) by non-opioid analgesics and/or their metabolites $(29,88,90)$;

2- Increase in endocannabinoid levels by;

a) inhibition of degradative enzymes;

i) via FAAH inhibition $(34,41)$;

ii) via COX-2 inhibition $(27,42,49)$;

b) shifting AA metabolism toward endocannabinoid synthesis due to COX inhibition (47-49);

c) reducing activation of endocannabinoid transporters and thus endocannabinoid degradation due to inhibition of NOS production $(96,97)$;

d) induction of endocannabinoid release $(70,94)$;

e) inhibition of cellular uptake of endocannabinoids by the metabolite (paracetamol) $(22,61)$.

\section{Endocannabinoid $_{\oplus} 7$ biosynthesis}
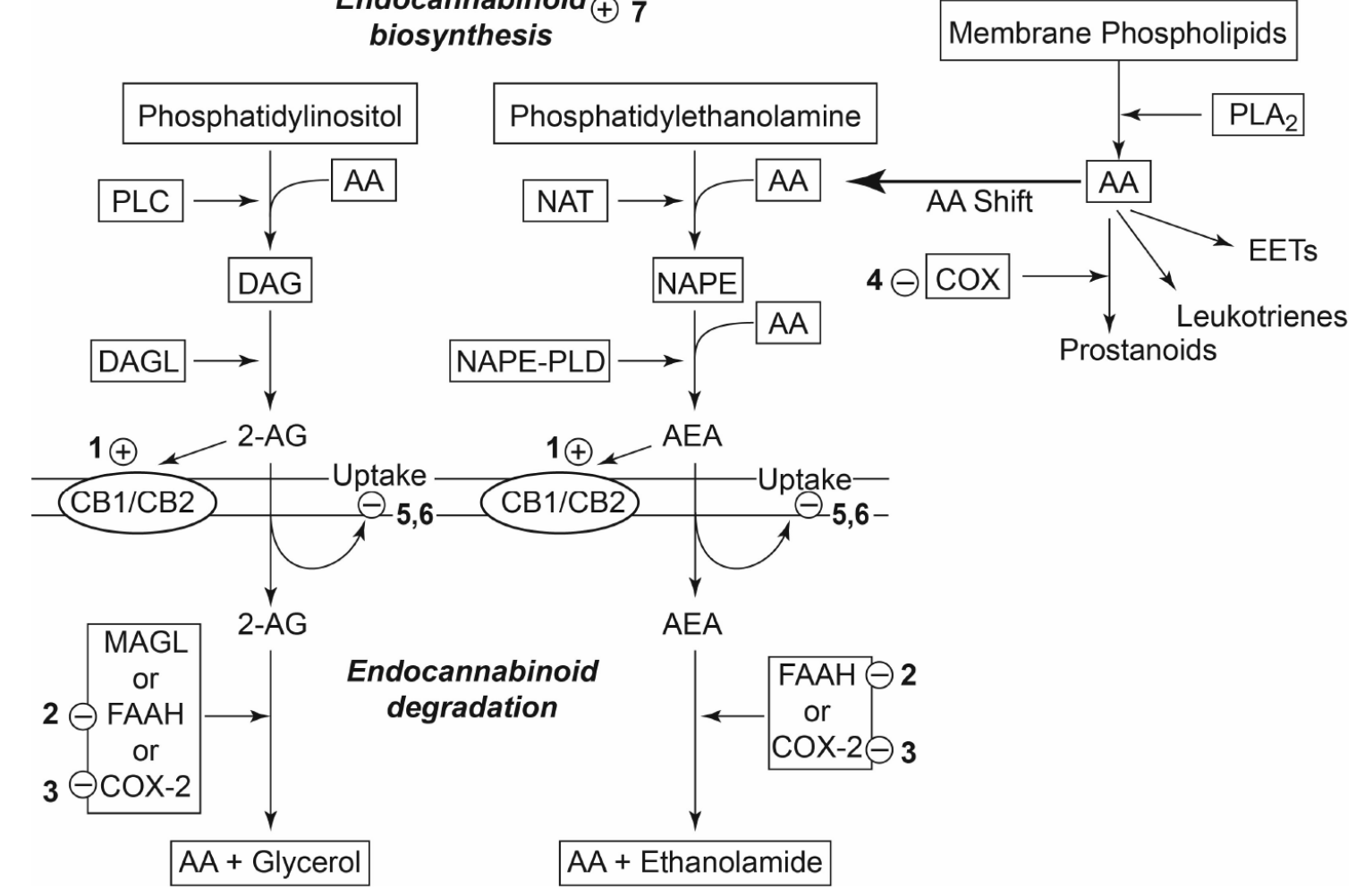

FIG. 1. Possible mechanisms of action regarding to contribution of the endocannabinoid system to the antinociceptive effects of non-opioid analgesics. Non-opioid analgesic drugs and their metabolites; 1) may activate cannabinoid receptors, 2, 3) may reduce endocannabinoid degradation via FAAH and/or COX-2 inhibition, 4) may induce arachidonic acid shift to endocannabinoid biosynthesis, 5, 6) may inhibit cellular uptake directly or via inhibiting nitric oxide synthase production, and finally 7 ) may stimulate endocannabinoid release. 
Conflict of Interest: No conflict of interest was declared by the authors.

Financial Disclosure: The authors declared that this study received no financial support.

\section{REFERENCES}

1. Pertwee RG. Cannabinoid receptors and pain. Prog Neurobiol 2001;63:569-611.

2. Grotenhermen F, Müller-Vahl K. The therapeutic potential of cannabis and cannabinoids. Dtsch Arztebl Int 2012;109:495-501.

3. Matsuda LA, Lolait SJ, Brownstein MJ, Young AC, Bonner TI. Structure of a Cannabinoid Receptor and Functional Expression of the Cloned Cdna. Nature 1990;346:561-4.

4. Munro S, Thomas KL, Abushaar M. Molecular characterization of a peripheral receptor for cannabinoids. Nature 1993;365:61-5.

5. Pertwee RG. The therapeutic potential of drugs that target cannabinoid receptors or modulate the tissue levels or actions of endocannabinoids. AAPS J 2005;7:625-54.

6. Pertwee RG. Targeting the endocannabinoid system with cannabinoid receptor agonists: pharmacological strategies and therapeutic possibilities. Philos Trans R Soc Lond B Biol Sci 2012;367:3353-63.

7. Guindon J, Hohmann AG. The Endocannabinoid System and Pain. CNS Neurol Disord Drug Targets 2009;8:403-21.

8. Di Marzo V. Endocannabinoids: synthesis and degradation. Rev Physiol Biochem Pharmacol 2008;160:1-24.

9. Zogopoulos P, Vasileiou I, Patsouris E, Theocharis SE. The role of endocannabinoids in pain modulation. Fundam Clin Pharmacol 2013;27:64-80.

10. Ulugöl A. The endocannabinoid system as a potential therapeutic target for pain modulation. Balkan Med J 2014;31:115-20.

11. Jhaveri MD, Richardson D, Chapman V. Endocannabinoid metabolism and uptake: novel targets for neuropathic and inflammatory pain. Brit J Pharmacol 2007;152:62432.

12. Kozak KR, Rowlinson SW, Marnett LJ. Oxygenation of the endocannabinoid, 2-arachidonylglycerol, to glyceryl prostaglandins by cyclooxygenase-2. J Biol Chem 2000;275:33744-9.

13. Kozak KR, Marnett LJ. Oxidative metabolism of endocannabinoids. Prostaglandins Leukot Essent Fatty Acids 2002;66:211-20.

14. Snider NT, Walker VJ, Hollenberg PF. Oxidation of the Endogenous Cannabinoid Arachidonoyl Ethanolamide by the Cytochrome P450 Monooxygenases: Physiological and Pharmacological Implications. Pharmacol Rev 2010;62:136-54.

15. Ulugol A, Karadag HC, Ipci Y, Tamer M, Dokmeci I. The effect of WIN 55,212-2, a cannabinoid agonist, on tactile allodynia in diabetic rats. Neurosci Lett 2004;371:167-70.

16. Ulugol A, Ozyigit F, Yesilyurt O, Dogrul A. The additive antinociceptive interaction between WIN 55,212-2, a cannabinoid agonist, and ketorolac. Anesth Analg 2006;102:443-7.

17. Gunduz O, Karadag HC, Ulugol A. Synergistic anti-allodynic effects of nociceptin/ orphanin FQ and cannabinoid systems in neuropathic mice. Pharmacol Biochem Behav 2011;99:540-4.

18. Wang T, Collet JP, Shapiro S, Ware MA. Adverse effects of medical cannabinoids: a systematic review. CMAJ 2008;178:1669-78.

19. Aizpurua-Olaizola O, Elezgarai I, Rico-Barrio I, Zarandona I, Etxebarria N, Usobiaga A. Targeting the endocannabinoid system: future therapeutic strategies. Drug Discov Today 2017;22:105-10.

20. Vemuri VK, Makriyannis A. Medicinal chemistry of cannabinoids. Clin Pharmacol Ther 2015;97:553-8.

21. Vane JR. Inhibition of Prostaglandin Synthesis as a Mechanism of Action for AspirinLike Drugs. Nature New Biol 1971;231:232-5.

22. Hamza M, Dionne RA. Mechanisms of non-opioid analgesics beyond cyclooxygenase enzyme inhibition. Curr Mol Pharmacol 2009;2:1-14.

23. Dogrul A, Gul H, Akar A, Yildiz O, Bilgin F, Guzeldemir E. Topical cannabinoid antinociception: synergy with spinal sites. Pain 2003;105:11-6.

24. Manzanares J, Julian MD, Carrascosa A. Role of the cannabinoid system in pain control and therapeutic implications for the management of acute and chronic pain episodes. Curr Neuropharmacol 2006;4:239-57.
25. Maione S, Radanova L, De Gregorio D, Luongo L, De Petrocellis L, Di Marzo V, et al. Effects of metabolites of the analgesic agent dipyrone (metamizol) on rostral ventromedial medulla cell activity in mice. Eur J Pharmacol 2015;748:115-22.

26. Vazquez E, Escobar W, Ramirez K, Vanegas H. A nonopioid analgesic acts upon the PAG-RVM axis to reverse inflammatory hyperalgesia. Eur J Neurosci 2007;25:471-9.

27. Fowler CJ. NSAIDs: eNdocannabinoid stimulating anti-inflammatory drugs? Trends Pharmacol Sci 2012;33:468-73

28. Mallet C, Daulhac L, Bonnefont J, Ledent C, Etienne M, Chapuy E, et al. Endocannabinoid and serotonergic systems are needed for acetaminophen-induced analgesia. Pain 2008;139:190-200.

29. Rogosch T, Sinning C, Podlewski A, Watzer B, Schlosburg J, Lichtman AH, et al. Novel bioactive metabolites of dipyrone (metamizol). Bioorg Med Chem 2012;20:101-7.

30. Schlosburg JE, Radanova L, Di Marzo V, Imming P, Lichtman AH. Evaluation of the endogenous cannabinoid system in mediating the behavioral effects of dipyrone (metamizol) in mice. Behav Pharmacol 2012;23:722-6.

31. Paria BC, Deutsch DD, Dey SK. The uterus is a potential site for anandamide synthesis and hydrolysis: Differential profiles of anandamide synthase and hydrolase activities in the mouse uterus during the periimplantation period. Mol Reprod Dev 1996;45:183-92.

32. Fowler CJ, Janson U, Johnson RM, Wahlström G, Stenström A, Norström A, et al Inhibition of anandamide hydrolysis by the enantiomers of ibuprofen, ketorolac, and flurbiprofen. Arch Biochem Biophys 1999;362:191-6.

33. Fowler CJ, Tiger G, Stenström A. Ibuprofen inhibits rat brain deamidation of anandamide at pharmacologically relevant concentrations. Mode of inhibition and structure-activity relationship. J Pharmacol Exp Ther 1997;283:729-34.

34. Karlsson J, Fowler CJ. Inhibition of Endocannabinoid Metabolism by the Metabolites of Ibuprofen and Flurbiprofen. Plos One 2014;9:e103589.

35. Fowler CJ, Holt S, Tiger G. Acidic nonsteroidal anti-inflammatory drugs inhibit rat brain fatty acid amide hydrolase in a pH-dependent manner. J Enzym Inhib Med Chem 2003;18:55-8.

36. Holt S, Fowler CJ. Anandamide metabolism by fatty acid amide hydrolase in intact C6 glioma cells. Increased sensitivity to inhibition by ibuprofen and flurbiprofen upon reduction of extra- but not intracellular pH. Naunyn Schmiedebergs Arch Pharmacol 2003;367:237-44

37. Holt S, Nilsson J, Omeir R, Tiger G, Fowler CJ. Effects of $\mathrm{pH}$ on the inhibition of fatty acid amidohydrolase by ibuprofen. Br J Pharmacol 2001;133:513-20.

38. Guindon J, Beaulieu P. Antihyperalgesic effects of local injections of anandamide, ibuprofen, rofecoxib and their combinations in a model of neuropathic pain. Neuropharmacology 2006;50:814-23.

39. Guindon J, De Lean A, Beaulieu P. Local interactions between anandamide, an endocannabinoid, and ibuprofen, a nonsteroidal anti-inflammatory drug, in acute and inflammatory pain. Pain 2006;121:85-93.

40. Holt S, Comelli F, Costa B, Fowler CJ. Inhibitors of fatty acid amide hydrolase reduce carrageenan-induced hind paw inflammation in pentobarbital-treated mice: comparison with indomethacin and possible involvement of cannabinoid receptors. Brit J Pharmacol 2005;146:467-76.

41. Fowler CJ, Björklund E, Lichtman AH, Naidu PS, Congiu C, Onnis V. Inhibitory properties of ibuprofen and its amide analogues towards the hydrolysis and cyclooxygenation of the endocannabinoid anandamide. J Enzym Inhib Med Chem 2013;28:172-82.

42. Duggan KC, Hermanson DJ, Musee J, Prusakiewicz JJ, Scheib JL, Carter BD, et al. (R)-Profens are substrate-selective inhibitors of endocannabinoid oxygenation by COX-2. Nat Chem Biol 2011;7:803-9.

43. Cipriano M, Björklund E, Wilson AA, Congiu C, Onnis V, Fowler CJ. Inhibition of fatty acid amide hydrolase and cyclooxygenase by the N-(3-methylpyridin-2-yl) amide derivatives of flurbiprofen and naproxen. Eur J Pharmacol 2013;720:38390 .

44. Prusakiewicz JJ, Duggan KC, Rouzer CA, Marnett LJ. Differential Sensitivity and Mechanism of Inhibition of COX-2 Oxygenation of Arachidonic Acid and 2-Arachidonoylglycerol by Ibuprofen and Mefenamic Acid. Biochemistry 2009;48:7353-5.

45. Naidu PS, Booker L, Cravatt BF, Lichtman AH. Synergy between enzyme inhibitors of fatty acid amide hydrolase and cyclooxygenase in visceral nociception. J Pharmacol Exp Ther 2009;329:48-56. 
46. Piscitelli F, Di Marzo V. "Redundancy" of Endocannabinoid Inactivation: New Challenges and Opportunities for Pain Control. ACS Chem Neurosci 2012;3:356-63.

47. Crunfli F, Vilela FC, Giusti-Paiva A. Cannabinoid CB1 receptors mediate the effects of dipyrone. Clin Exp Pharmacol Physiol 2015;42:246-55.

48. Pestonjamasp VK, Burstein SH. Anandamide synthesis is induced by arachidonate mobilizing agonists in cells of the immune system. Biochim Biophys Acta 1998;1394:249-60.

49. Gühring H, Hamza M, Sergejeva M, Ates M, Kotalla CE, Ledent C, et al. A role for endocannabinoids in indomethacin-induced spinal antinociception. Eur J Pharmacol 2002;454:153-63.

50. Ates M, Hamza M, Seidel K, Kotalla CE, Ledent C, Gühring H. Intrathecally applied flurbiprofen produces an endocannabinoid-dependent antinociception in the rat formalin test. Eur J Neurosci 2003;17:597-604.

51. Rezende RM, Paiva-Lima P, Dos Reis WGP, Camelo VM, Faraco A, Bakhle YS, et al. Endogenous Opioid and Cannabinoid Mechanisms Are Involved in the Analgesic Effects of Celecoxib in the Central Nervous System. Pharmacology 2012;89:127-36.

52. Silva LCR, Romero TRL, Guzzo LS, Duarte IDG. Participation of cannabinoid receptors in peripheral nociception induced by some NSAIDs. Braz J Med Biol Res 2012;45:1240-3.

53. Chatzisali B, Gaş T, Kılgın H, Duvan Aydemir K, Erümit D, Topuz RD, et al. Cannabinoid receptors are not involved in antinociception induced by systemic diclofenac in mice. Turkish Med Stud J 2020;7:1-4.

54. Anikwue R, Huffman JW, Martin ZL, Welch SP. Decrease in efficacy and potency of nonsteroidal anti-inflammatory drugs by chronic Delta(9)-tetrahydrocannabinol administration. J Pharmacol Exp Ther 2002;303:340-6.

55. Staniaszek LE, Norris LM, Kendall DA, Barrett DA, Chapman V. Effects of COX2 inhibition on spinal nociception: the role of endocannabinoids. Br J Pharmacol 2010;160:669-76.

56. Jozwiak-Bebenista M, Nowak JZ. Paracetamol: Mechanism of Action, Applications and Safety Concern. Acta Pol Pharm 2014;71:11-23.

57. Bujalska M. Effect of nonselective and selective opioid receptors antagonists on antinociceptive action of acetaminophen [Part III]. Pol J Pharmacol 2004;56:539-45.

58. Flower RJ, Vane JR. Inhibition of Prostaglandin Synthetase in Brain Explains the Anti-Pyretic Activity of Paracetamol (4-Acetamidophenol). Nature 1972;240:410-1.

59. Pini LA, Sandrini M, Vitale G. The antinociceptive action of paracetamol is associated with changes in the serotonergic system in the rat brain. Eur J Pharmacol 1996;308:31-40.

60. Ryu YS, Lee JH, Seok JH, Hong JH, Lee YS, Lim JH, et al. Acetaminophen inhibits iNOS gene expression in RAW 264.7 macrophages: Differential regulation of NF-kappaB by acetaminophen and salicylates. Biochem Bioph Res Commun 2000;272:758-64.

61. Högestätt ED, Jönsson BA, Ermund A, Andersson DA, Björk H, Alexander JP, et al. Conversion of acetaminophen to the bioactive N-acylphenolamine AM404 via fatty acid amide hydrolase-dependent arachidonic acid conjugation in the nervous system. J Biol Chem 2005;280:31405-12.

62. Dani M, Guindon J, Lambert C, Beaulieu P. The local antinociceptive effects of paracetamol in neuropathic pain are mediated by cannabinoid receptors. Eur $\mathrm{J}$ Pharmacol 2007;573:214-5.

63. Ottani A, Leone S, Sandrini M, Ferrari A, Bertolini A. The analgesic activity of paracetamol is prevented by the blockade of cannabinoid CB1 receptors. Eur J Pharmacol 2006;531:280-1.

64. Di Marzo V, Bisogno T, De Petrocellis L, Brandi I, Jefferson RG, Winckler RL, et al. Highly selective CB1 cannabinoid receptor ligands and novel CB1/VR1 vanilloid receptor "hybrid" ligands. Biochem Biophys Res Commun 2001;281:444-51.

65. Giuffrida A, Beltramo M, Piomelli D. Mechanisms of endocannabinoid inactivation: Biochemistry and pharmacology. J Pharmacol Exp Ther 2001;298:7-14.

66. Glaser ST, Abumrad NA, Fatade F, Kaczocha M, Studholme KM, Deutsch DG. Evidence against the presence of an anandamide transporter. Proc Natl Acad Sci U S A 2003;100:4269-74.

67. Zygmunt PM, Chuang H, Movahed P, Julius D, Högestatt ED. The anandamide transport inhibitor AM404 activates vanilloid receptors. Eur J Pharmacol 2000;396:3942 .

68. Hama AT, Sagen J. Cannabinoid receptor-mediated antinociception with acetaminophen drug combinations in rats with neuropathic spinal cord injury pain. Neuropharmacology 2010;58:758-66.
69. Haller VL, Cichewicz DL, Welch SP. Non-cannabinoid CB1, non-cannabinoid CB2 antinociceptive effects of several novel compounds in the PPQ stretch test in mice. Eur J Pharmacol 2006;546:60-8.

70. Topuz RD, Gunduz O, Karadag HC, Dokmeci D, Ulugol A. Endocannabinoid and $\mathrm{N}$-acylethanolamide levels in rat brain and spinal cord following systemic dipyrone and paracetamol administration. Can J Physiol Pharmacol 2019;97:1035-41.

71. Umathe SN, Manna SSS, Utturwar KS, Jain NS. Endocannabinoids mediate anxiolyticlike effect of acetaminophen via CB1 receptors. Prog Neuropsychopharmacol Biol Psychiatry 2009;33:1191-9.

72. Gould GG, Seillier A, Weiss G, Giuffrida A, Burke TF, Hensler JG, et al Acetaminophen differentially enhances social behavior and cortical cannabinoid levels in inbred mice. Prog Neuropsychopharmacol 2012;38:260-9.

73. Saglam G, Gunduz O, Ulugol A. Blockade of cannabinoid CB1 and CB2 receptors does not prevent the antipruritic effect of systemic paracetamol. Acta Neurol Belg 2014;114:307-9.

74. Akman H, Aksu F, Gultekin I, Ozbek H, Oral U, Doran F, et al. A possible central antinociceptive effect of dipyrone in mice. Pharmacology 1996;53:71-8.

75. Carlsson KH, Jurna I. The Role of Descending Inhibition in the Antinociceptive Effects of the Pyrazolone Derivatives, Metamizol (Dipyrone) and Aminophenazone (Pyramidon). Naunyn Schmiedebergs Arch Pharmacol 1987;335:154-9.

76. Gencer A, Gunduz O, Ulugol A. Involvement of descending serotonergic and noradrenergic systems and their spinal receptor subtypes in the antinociceptive effect of dipyrone. Drug Res (Stuffg) 2015;65:645-9.

77. Vasquez E, Vanegas H. The antinociceptive effect of PAG-microinjected dipyrone in rats is mediated by endogenous opioids of the rostral ventromedial medulla. Brain Res 2000;854:249-52.

78. Vanegas H, Tortorici V. Opioidergic effects of nonopioid analgesics on the central nervous system. Cell Mol Neurobiol 2002;22:655-61.

79. Hernandez N, Vanegas $\mathrm{H}$. Antinociception induced by PAG-microinjected dipyrone (metamizol) in rats: involvement of spinal endogenous opioids. Brain Res $2001 ; 896: 175-8$

80. Tortorici V, Vanegas H. Opioid tolerance induced by metamizol (dipyrone) microinjections into the periaqueductal grey of rats. Eur J Neurosci 2000;12:4074-80.

81. Vazquez E, Hernandez N, Escobar W, Vanegas H. Antinociception induced by intravenous dipyrone (metamizol) upon dorsal horn neurons: involvement of endogenous opioids at the periaqueductal gray matter, the nucleus raphe magnus, and the spinal cord in rats. Brain Res 2005;1048:211-7.

82. Campos C, de Gregorio R, Garcia-Nieto R, Gago F, Ortiz P, Alemany S. Regulation of cyclooxygenase activity by metamizol. Eur J Pharmacol 1999;378:339-47.

83. Lorenzetti BB, Ferreira SH. Activation of the arginine-nitric oxide pathway in primary sensory neurons contributes to dipyrone-induced spinal and peripheral analgesia. Inflamm Res 1996;45:308-11.

84. Miranda HF, Noriega V, Sierralta F, Poblete P, Aranda N, Prieto JC. Nitric Oxide and Opioids Involvement in Isobolographic Nsaids Antinociception. Drug Res (Stuttg) 2019;69:688-94.

85. Yilmaz I, Ulugol A. The effect of nitric oxide synthase Inhibitors on the development of analgesic tolerance to dipyrone in mice. Int J Neurosci 2009;119:755-64.

86. Escobar W, Ramirez K, Avila C, Limongi R, Vanegas H, Vazquez E. Metamizol, a non-opioid analgesic, acts via endocannabinoids in the PAG-RVM axis during inflammation in rats. Eur J Pain 2012;16:676-89.

87. Elmas P, Ulugol A. Involvement of cannabinoid CB1 receptors in the antinociceptive effect of dipyrone. J Neural Transm (Vienna) 2013;120:1533-8.

88. dos Santos GG, Dias EV, Teixeira JM, Athie MC, Bonet IJ, Tambeli CH, et al. The analgesic effect of dipyrone in peripheral tissue involves two different mechanisms: Neuronal K (ATP) channel opening and CB (1) receptor activation. Eur J Pharmacol 2014;741:124-31.

89. Russo S, de Azevedo WF Jr. Computational Analysis of Dipyrone Metabolite 4-Aminoantipyrine as a Cannabinoid Receptor 1 Agonist. Curr Med Chem 2019 Sep 6. PubMed PMID: 31490743. Epub 2019/09/07.

90. Gonçalves Dos Santos G, Vieira WF, Vendramini PH, Bassani da Silva B, Fernandes Magalhães $\mathrm{S}$, Tambeli $\mathrm{CH}$, et al. Dipyrone is locally hydrolyzed to 4-methylaminoantipyrine and its antihyperalgesic effect depends on CB2 and kappaopioid receptors activation. Eur J Pharmacol 2020;874:173005.

91. Topuz RD, Gunduz O, Dokmeci D, Karadag CH, Ulugol A. Does dipyrone produce anxiolytic-like effects in mice? Cukurova Med J 2019;44:866-74 (in Turkish). 
92. Vaughan CW, Connor M, Bagley EE, Christie MJ. Actions of cannabinoids on membrane properties and synaptic transmission in rat periaqueductal gray neurons in vitro. Mol Pharmacol 2000;57:288-95.

93. Dogrul A, Seyrek M, Yalcin B, Ulugol A. Involvement of descending serotonergic and noradrenergic pathways in CB1 receptor-mediated antinociception. Prog Neuropsychopharmacol Biol Psychiatry 2012;38:97-105.

94. Vanegas H, Vazquez E, Tortorici V. NSAIDs, opioids, cannabinoids and the control of pain by the central nervous system. Pharmaceuticals (Basel) 2010;3:1335-47.
95. Vaughan CW, McGregor IS, Christie MJ. Cannabinoid receptor activation inhibits GABAergic neurotransmission in rostral ventromedial medulla neurons in vitro. Brit J Pharmacol 1999;127:935-40.

96. Bisogno T, Maccarrone M, De Petrocellis L, Jarrahian A, Finazzi-Agro A, Hillard $\mathrm{C}$, et al. The uptake by cells of 2-arachidonoylglycerol, an endogenous agonist of cannabinoid receptors. Eur J Biochem 2001;268:1982-9.

97. Maccarrone M, Bari M, Lorenzon T, Bisogno T, Di Marzo V, Finazzi-Agro A. Anandamide uptake by human endothelial cells and its regulation by nitric oxide. $\mathrm{J}$ Biol Chem 2000;275:13484-92. 